\title{
Huertos, chacras y sementeras. Plantas cultivadas y su participación en los desarrollos culturales de Chile central
}

\author{
María Teresa Planella \\ Sociedad Chilena de Arqueología \\ mtplanella@gmail.com \\ Fernanda FALABELLA \\ Departamento de Antropología, Universidad de Chile \\ ffalabella@vtr.net \\ Carolina BELMAR \\ Departamento de Antropología, Universidad de Chile \\ carolina_belmar@hotmail.com \\ Luciana QUIROZ \\ Investigadora independiente \\ lucianaquiroz@hotmail.com
}

Recibido: 9 de septiembre de 2013

Aceptado: 15 de abril de 2014

\begin{abstract}
RESUMEN
En Chile central las evidencias arqueobotánicas aún no avalan lo suficiente una descripción de los procesos de domesticación de plantas. No obstante, la presencia de cultivos en los contextos arqueológicos desde hace unos 3.500 años desvela la incorporación paulatina y el manejo de especies cultivadas americanas de origen no local, como el Zea mays L. (maíz), y otras de probable sustrato local como Madia sativa Mol. (madi). En este artículo se presentan los datos disponibles sobre la presencia y utilización de estas especies en los distintos momentos del desarrollo prehispánico, sobre la base de macrorrestos y microrrestos recuperados en sedimentos y artefactos arqueológicos y de isótopos estables. Esta información, si bien aún escasa y fragmentaria, permite señalar que las plantas fueron parte del universo ideacional y cultural, participando activamente en la configuración de los modos de vida e identidades sociales. De esta forma, las distintas especies tuvieron roles particulares en los diversos grupos humanos que poblaron esta zona en tiempos prehispánicos.
\end{abstract}

Palabras clave: Chile central prehispánico, plantas domesticadas, Zea mays, Chenopodium quinoa.

\section{Gardens, Chacras, and Sementeras. Cultivated Plants and their Participation in Cultural Developments in Central Chile}

\begin{abstract}
Archaeobotanical data from Central Chile do not yet provide solid evidence to back a description of local plant domestication processes; nevertheless, domesticated plants where progressively incorporated and manipulated by local groups at least since $3500 \mathrm{BP}$ in this region. Some were non local cultivated American species, as Zea mays L. (maize), and others probably developed locally, as Madia sativa Mol. (madi). This paper describes the data available for these plants during different prehispanic periods, based on macro and micro remains recovered from sediments and archaeological artefacts, and on stable isotopes information. We argue that, even if data are still scarce and fragmentary, cultivated plants were part of the ideational and cultural environment and actively participated in defining life styles and social identities. Plants played different roles for specific human groups inhabiting Central Chile during prehispanic times.
\end{abstract}

Key words: Prehispanic Central Chile, domesticated plants, Zea mays, Chenopodium quinoa.

Sumario: 1. Introducción. 2. Características de la región. 3. Los primeros cultígenos entre cazadores recolectores de fines del período Arcaico. 4. Las primeras comunidades alfareras. 5. Los grupos Bato del período 
Alfarero Temprano. 6. Los grupos Llolleo del período Alfarero Temprano y la incorporación de nuevos cultígenos. 7. Los grupos Aconcagua del período Intermedio Tardío. 8. Contacto con el Tawantinsuyu durante el período Tardío. 9. Conclusiones. 10. Referencias bibliográficas.

\section{Introducción}

Cuando llegan los españoles a la región central de Chile advirtieron extensos campos cultivados o «sementeras» que proveían de alimento a la población indígena local. La experiencia previa con pueblos de Mesoamérica y Los Andes les hizo reconocer el maíz, papa, quinoa, zapallo, porotos, un conjunto de productos que a lo largo de milenios fueron manipulados y utilizados, entre otras plantas cultivadas, por los indígenas en distintos rincones de América. Ningún relato oral transmitió información sobre cómo estos productos llegaron a ser parte de la cultura alimentaria indígena. Sería la arqueología el medio que paulatinamente y con grandes dificultades, empezó a arrojar luz sobre una historia de la cual aún queda mucho por contar y ofrecer el contexto dentro del cual se desarrolló. Estas y otras plantas fueron domesticadas a partir de ancestros silvestres en uno o más lugares del continente, se dispersaron por él y en ese proceso se fueron modificando (Lavallée 2000). La reconstrucción de la historia y etapas de la domesticación de plantas ha tenido amplia investigación especialmente en Mesoamérica y los Andes Centrales, focos importantes de procesos originarios de domesticación y lugares desde donde probablemente se dispersaron la mayoría de las plantas utilizadas por la población amerindia.

En Chile central la línea de investigación arqueobotánica es comparativamente muy reciente. Las características de suelo y clima en esta zona facilitan la descomposición de la materia orgánica dificultando la recuperación de vestigios a menos que éstos hayan estado sometidos a carbonización. El hallazgo de órganos vegetales desecados es excepcional. Esta ha sido una limitante para conseguir series de restos vegetales cualitativa y cuantitativamente significativas con el fin de obtener mayores indicadores de los hábitos y productos de consumo de las poblaciones pretéritas de esta región y otras al sur. Pese a ello, la técnica de flotación, en uso solo desde hace unos 15 años en nuestro país, ha contribuido notablemente a ampliar el espectro del registro arqueológico y el estudio de macrorrestos, lo que ha permitido la identificación de especies de los depósitos culturales y del entorno natural de los sitios. Por otra parte, los análisis de microrrestos en los últimos años, han maximizado el potencial de recuperación de la información contenida en sedimentos, en residuos adheridos en artefactos y otras expresiones de la cultura material, como por ejemplo las piedras tacitas. No obstante, el volumen de sedimentos y la irregularidad de los protocolos atentan contra una comparación regional cuantitativa sólida. La información sobre las características de las especies y sus transformaciones a través del tiempo o entre localidades es muy escasa y proviene en muchos casos de sitios puntuales. En este trabajo entregamos esta información y ofrecemos algunas posibilidades interpretativas sobre las plantas cultivadas y su desarrollo basados en este cuerpo de datos algo desequilibrado, que deberá ser complementado, verificado y/o corregido en futuras investigaciones (Cuadro 1). 
Cuadro 1: Plantas cultivadas presentes en depósitos arqueológicos de los distintos grupos culturales en los períodos prehispánicos discutidos en el texto

\begin{tabular}{|c|c|c|c|}
\hline Período & Fechas & $\begin{array}{c}\text { Grupo } \\
\text { Cultural }\end{array}$ & Cultígenos asociados \\
\hline Arcaico IV & 3000 a 300 a.C. & & Quinoa de nivel de mar (Chenopodium quinoa Willd.) \\
\hline \multirow{3}{*}{$\begin{array}{l}\text { Alfarero } \\
\text { Temprano }\end{array}$} & 300 a.C. a 200 d.C. & $\begin{array}{l}\text { Comunidades } \\
\text { Alfareras } \\
\text { Iniciales }\end{array}$ & Quinoa de nivel de mar (Chenopodium quinoa Willd.) \\
\hline & 200 a 1200 d.C. & $\begin{array}{l}\text { Complejo } \\
\text { Cultural } \\
\text { Bato }\end{array}$ & $\begin{array}{l}\text { Quinoa de nivel de mar(Chenopodium quinoa Willd.) } \\
\text { Maíz variedad curagua (Zea mays L.) } \\
\text { Madi (Madia sativa Mol.) } \\
\text { Calabaza (Lagenaria } \text { spp. Ser.) }\end{array}$ \\
\hline & 400 a 1200 d.C. & $\begin{array}{l}\text { Complejo } \\
\text { Cultural } \\
\text { Llolleo }\end{array}$ & $\begin{array}{l}\text { Quinoa de nivel de mar (Chenopodium quinoa Willd.) } \\
\text { Maíz variedad curagua (Zea mays L.) } \\
\text { Poroto (Phaseolus spp., Phaseolus vulgaris L.) } \\
\text { Zapallo (Curcurbita spp.) } \\
\text { Calabaza (Lagenaria spp. Ser.) } \\
\text { Teca (Bromus berteroanus Colla) } \\
\text { Magu (Bromus mango É.Desv.) }\end{array}$ \\
\hline $\begin{array}{l}\text { Intermedio } \\
\text { Tardío }\end{array}$ & $\begin{array}{l}\text { 1000/1200 a } \\
1450 \text { d.C. }\end{array}$ & $\begin{array}{l}\text { Complejo } \\
\text { Cultural } \\
\text { Aconcagua }\end{array}$ & $\begin{array}{l}\text { Quinoa de nivel de mar (Chenopodium quinoa Willd.) } \\
\text { Quinoa altiplánica ¿? (Chenopodium quinoa Willd.) } \\
\text { Maíz (Zea mays L.) } \\
\text { Poroto (Phaseolus spp., Phaseolus vulgaris L.) } \\
\text { Poroto pallar (Phaseolus lunatus L.) } \\
\text { Zapallo (Curcurbita } \text { spp.) } \\
\text { Madi (Madia sativa Mol.) }\end{array}$ \\
\hline Tardío & 1450 a 1540 d.C. & $\begin{array}{l}\text { Aconcagua } \\
\text { Diaguita Inka }\end{array}$ & $\begin{array}{l}\text { Quinoa de nivel de mar (Chenopodium quinoa Willd.) } \\
\text { Quinoa altiplánica (Chenopodium quinoa Willd.) } \\
\text { Maíz (Zea mays L.) } \\
\text { Poroto (Phaseolus spp., Phaseolus vulgaris L.) } \\
\text { Poroto pallar (Phaseolus lunatus L.) } \\
\text { Zapallo (Curcurbita spp.) } \\
\text { Calabaza (Lagenaria spp. Ser.) } \\
\text { Ají (Capsicum spp.) } \\
\text { Papa (Solanum spp.) } \\
\text { Madi (Madia sativa Mol.) } \\
\text { Madi (Madia chilensis (Nutt) Reiche) } \\
\text { Maravilla (Helianthus } \text { cf. tuberosus L.) }\end{array}$ \\
\hline
\end{tabular}

\section{Características de la región}

La región central de Chile abarca desde el río Choapa por el norte $\left(31^{\circ} 50^{\prime} \mathrm{S}\right)$ hasta el río Maule por el sur $\left(35^{\circ} 40^{\prime} \mathrm{S}\right)$ coincidente con el primitivo núcleo histórico de actividades agrícolas extensivas (Santana 1966). En este artículo, no obstante, la información que se entrega comprende el espacio entre los ríos Aconcagua y Cachapoal por ser la zona donde se han desarrollado las investigaciones arqueológicas que aportan datos sobre la dispersión de plantas cultivadas (Figura 1).

En su caracterización geomorfológica se conoce como región central de las cuencas y del llano fluvio-glacio-volcánico, con cuatro definidas macroformas del relieve que se desarrollan en sentido norte-sur en un ancho máximo de $190 \mathrm{~km}$ : Planicies 


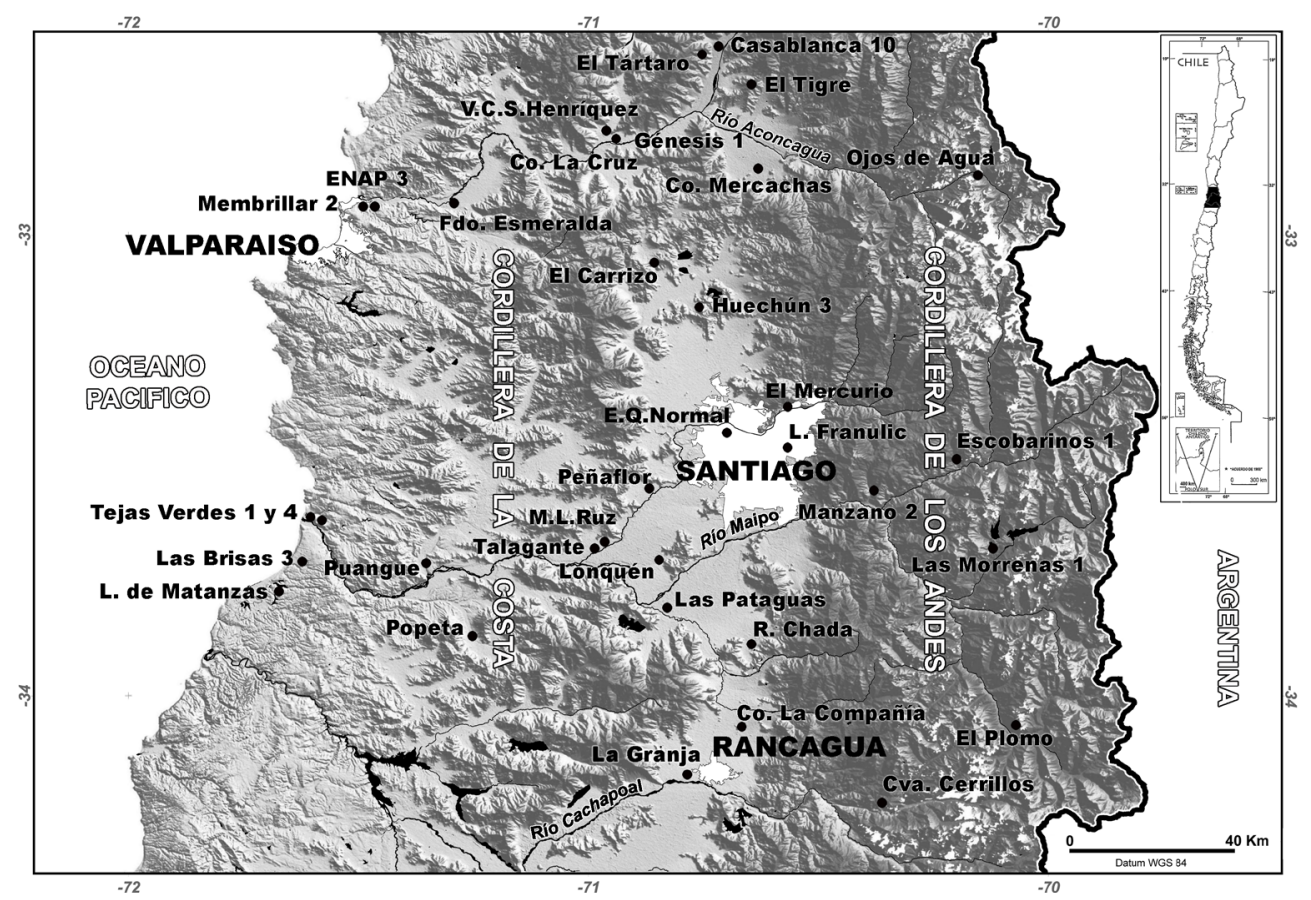

Figura 1: Mapa de Chile central con los sitios arqueológicos mencionados en el texto

litorales, Cordillera de la Costa con alturas promedio de $2.000 \mathrm{msnm}$, Depresión intermedia y Cordillera de los Andes con alturas de hasta $6.000 \mathrm{msnm}$ que van decreciendo hacia latitudes mayores. Las formaciones orográficas de la Cordillera de la Costa permiten la existencia de valles de fondo plano, originados por aluviones ricos en limos fluviales con gran aporte de fertilizantes naturales, y en donde se producen notables condiciones de microclimas. Estos distintos ecosistemas tienen un enorme potencial en variados recursos naturales y una gran biodiversidad de su fauna y de su flora silvestre, que incluye especies endémicas y exclusivas que ofrecen una favorable disponibilidad estacional de productos comestibles. Esas condiciones han sustentado la movilidad y economía desde los antiguos habitantes de la región, enraizando un sentido de predictibilidad según estos ciclos para la oportuna actividad de recolección en determinadas épocas del año (Planella et al. 2010b).

La zona central de Chile presenta un clima templado de tipo mediterráneo, con oscilaciones térmicas moderadas, y con un ciclo anual dividido en cuatro estaciones que presentan temperaturas medias de entre $8,8^{\circ}$ y $18,2^{\circ} \mathrm{C}$, con una amplitud térmica anual de $10,1^{\circ} \mathrm{C}$ entre los meses de invierno y verano (Fuenzalida 1966). Las lluvias se concentran entre otoño y primavera, con precipitaciones que alcanzan los 360 a $450 \mathrm{~mm}$ anuales en las cuencas interiores y algo más en la costa favoreciendo, junto con las abundantes cuotas de aguas de deshielo, las actividades de siembra y cosecha de productos en las estaciones siguientes. Estas favorables condiciones climáticas fueron advertidas y realzadas tempranamente, entre otros, por los testimonios de Val- 
divia (1960 [1545]) y Vivar (1979[1558]).Si bien en las cuencas interiores y valles la abundancia de recursos hídricos puede suplir la ausencia de lluvias para el regadío, en las zonas de secano costero o de "rulo»" ${ }^{1}$ las lluvias son determinantes y condicionan las actividades hortícolas o agrícolas, incluyendo los cultivos que se adaptan a esta condición. Una fuente de agua importante fueron las paleolagunas que revelan evidencias de actividad humana desde el pleistoceno (Núñez et al. 1994).

Las características de los suelos de la zona central han posibilitado desarrollar hasta épocas recientes, tanto en las amplias cuencas interiores con extensos y fértiles terrenos planos de origen aluvial y fluvial ricos en potasio, fósforo y nitrógeno, como en pequeños valles y terrazas de la cordillera andina y de la costa, una horticultura tradicional que no requiere de gran tecnología. La gran fertilidad del suelo descrita y el potencial de terrenos aptos para el cultivo, se extienden a latitudes mayores hacia el sur de la región central, lo que ha ampliado territorial y económicamente las posibilidades de actividades de subsistencia relacionadas con la horticultura o agricultura ${ }^{2}$ desde tiempos pretéritos, apoyando luego y enraizando los tempranos asentamientos hispánicos.

\section{Los primeros cultígenos entre cazadores recolectores de fines del período Arcaico}

La proximidad al mundo vegetal que vivenciaron los cazadores recolectores del Holoceno, necesariamente debió traducirse en un conocimiento profundo de los ciclos de vida de la vegetación, sus bondades y su utilización en distintas necesidades y aspectos de la vida cotidiana, como también el contenido en sustancias peligrosas por su toxicidad. La gran disponibilidad de especies vegetales en el entorno de los grupos cazadores recolectores que habitaron Chile central, proveyó de recursos alimenticios anexos al acceso a la carne de guanaco u otra fauna silvestre; por otra parte, condiciones de orden social, ritual o simbólico pueden haber estimulado el conocimiento, la adquisición y/o manejo de otras especies con mayor valor nutricional. Es el caso de una variedad temprana domesticada de quinoa (Chenopodium cf Chenopodium quinoa) (López et al. 2015), el primer recurso vegetal con rasgos de intervención humana encontrado en la zona central de Chile, cuyos antiguos vestigios han sido registrados en el sector altoandino de la cordillera de los Andes en las basuras y fogones de sitios de grupos cazadores recolectores de fines del Arcaico IV (3000 a 300 a.C.) (Cornejo et al. 1998).

Tres aspectos son especialmente relevantes de estos grupos cordilleranos. Por una parte, el período Arcaico IV es un momento de cambio desde estrategias de movilidad residencial a movilidad logística, con campamentos base de más larga duración y

1 Lenz (1905-1910: 688) lo define como tierra de labor que no tiene riego de acequias y solo recibe agua de la lluvia.

2 La horticultura se caracteriza por el uso de áreas de producción reducidas, cerca de la unidad doméstica, donde se cultivan un conjunto diverso de taxa. Por lo general su finalidad es el autoconsumo e implica el uso de un equipo tecnológico simple. La agricultura en cambio, implica mayor extensión de cultivos, intensidad y rendimiento de los mismos y en consecuencia la necesidad de incrementar la mano de obra y/o tecnología (Harris y Hillman 1989). 
con un incremento de la importancia de los vegetales en la dieta (Cornejo y Sanhueza 2011a). Por otra, las evidencias provienen de sitios localizados en el alto Maipo, cercano a un paso cordillerano bajo, que facilitaría la integración de las vertientes oriental y occidental de los Andes dentro de circuitos de movilidad de cazadores recolectores, en los que incluso podrían participar grupos familiares completos (Cornejo y Sanhueza 2011b). Por último, Cornejo y Sanhueza (2011a y b) han planteado la coexistencia de dos comunidades de cazadores-recolectores en este sector de la vertiente occidental de la cordillera, con diferentes formas de ocupar el espacio y de organizar las relaciones sociales y las redes de acceso a bienes, y ambos reflejan el conocimiento y eventual consumo de Chenopodium. Las evidencias se han recuperado de dos sitios: Las Morrenas 1 y El Plomo, localizados frente a la ciudad de Santiago a 2070 y $2500 \mathrm{msnm}$, que fueron ocupados temporalmente aprovechando las estaciones de deshielo y ausencia de nieves, entre los meses de agosto/septiembre hasta marzo/abril. El sitio El Plomo (1460 a 1340 a.C.) evidencia Chenopodium cf. C. quinoa, con cantidades similares entre ejemplares carbonizados y otros en condición desecada. Estos últimos no presentan radícula, no alcanzan tamaños mayores a 0,8 a $1 \mathrm{~mm}$ de diámetro y conservan una coloración natural blanco-marfil del perisperma, margen truncado/redondeado, ausencia de testa y prominencia del embrión (beak) (Planella et al. 2011). Por su parte, en el alero Las Morrenas 1 (1250 a 980 a.C. fechado AMS directo en semillas) se recuperó Chenopodium cf. C. quinoa. En este sitio todos los ejemplares están carbonizados, lo que impide su adscripción taxonómica a nivel de variedad o de especie. La mayoría presenta la radícula desprendida del resto de la semilla o el extremo de la misma está hinchado o levantado supuestamente por la carbonización (Planella et al. 2005).

Esta zona continuó siendo ocupada por cazadores-recolectores hasta tiempos de la Colonia, los que deben haber sido agentes permanentes de contactos, comunicación e intercambio con la vertiente oriental de Los Andes. Muchos sitios del Arcaico IV fueron ocupados durante el período Alfarero Temprano, con el mismo énfasis de la tecnología lítica arcaica y utilizando contenedores cerámicos probablemente obtenidos de los horticultores del valle (Cornejo y Sanhueza 2003).

Se ha discutido acerca de la existencia de ancestros y manipulación local de Amaranthaceae en la región central, o si el género Chenopodium llegó por vía de difusión natural seminal o por contactos entre grupos humanos. Sobre este tema existen al menos tres líneas de investigación que requieren aún de mayor atención, de datos arqueológicos y estudios de ecosistemas. Una de ellas la conforman los estudios de polen (Villa Martínez et al. 2003, entre otros) que indican la presencia/disponibilidad de Amaranthaceae en las columnas analizadas en esta región, durante el Holoceno. Otra línea son las evidencias arqueológicas en la alta cordillera ${ }^{3}$ recién mencionadas. Una tercera línea es la existencia hasta la actualidad, en los valles de la Cordillera de la Costa de las provincias de $\mathrm{O}^{\prime}$ Higgins y Maule $\left(34^{\circ}\right.$ a $\left.35^{\circ} \mathrm{S}\right)$ y hasta una cota de 300 msnm, de cultivos de una particular subespecie de quinoa llamada «de nivel de mar», quinoa costera, quinwa o dahue (etnónimo mapuche) (Bertero 2007; Tapia 1979;

3 Las excavaciones en sitios del período Arcaico tardío en valles y costa son muy escasas, por lo que no se puede determinar si existen estos mismos contextos arqueobotánicos fuera de la cordillera. 
Wilson 1988) que presenta atributos relictuales, como la inflorescencia glomerulada de sus panojas y el perisperma siempre traslúcido de sus semillas que la distinguen de la quinoa altoandina. Su reducido tamaño es común con los vestigios recuperados en distintos sitios arqueológicos de la región central de Chile y que se modifica en el período Intermedio Tardío con especímenes de diámetro mayor (Planella et al. 2005). El común estado de carbonización no permite visualizar si el perisperma es cristalino, como el del ecotipo «de nivel de mar» (Tapia 1979), o si es opaco como en la quinoa altiplánica (Tagle y Planella 2002).

Wilson (1988) señala que la presencia de un perisperma traslúcido y la inflorescencia glomerulada, ambos rasgos arcaicos asociados a variedades silvestres, sugieren que los grupos costeros existentes se derivaron de la quinoa andina en forma previa al desarrollo del perisperma harinoso y la inflorescencia amarantiforme en las tierras altoandinas. Para este autor la quinwa o dahue también estudiada en la isla de Chiloé, constituye una forma arcaica de quinoa derivada en épocas pretéritas de ancestros que experimentaron diferenciaciones significativas en las tierras altoandinas. Según Bertero (2007), la evidencia basada en el análisis de los patrones de interacción genotipo por ambiente, datos morfométricos, de comparación de isoenzimas, de caracterización molecular de germoplasma usando diferentes marcadores y su particular adaptación a baja altitud, coinciden en señalar a estos materiales de nivel de mar como un grupo separado de aquellos andinos.

\section{Las primeras comunidades alfareras}

Las Comunidades Alfareras Iniciales (300 a.C. a 200 d.C.) representan los primeros grupos que usan tecnología alfarera en la región. Presentan similitudes con los cazadores-recolectores del período Arcaico anterior, en especial en las tradiciones líticas orientadas a la caza, lo que sugiere continuidad en algunos aspectos de los modos de vida (Sanhueza y Falabella 1999-2000). La quinoa domesticada aparece, en la mayoría de ellos, asociada siempre a una gran variedad de productos silvestres, leguminosas y gramíneas. Si bien los sitios investigados son escasos, se ha registrado Chenopodium quinoa en el sitio Lenka Franulic, en la capa inferior del sitio Lonquén (85 \pm 200 a.C., $105 \pm 200$ a.C.) (Sanhueza et al. 2003), en enterramientos del sitio El Mercurio desde la Fase I (120 \pm 180 d.C., $150 \pm 150$ d.C.) (Falabella 2000a), desde los niveles más antiguos en el sitio La Granja (110 a 550 cal d.C) y, con fechas algo más tardías, en el sitio Estación Quinta Normal (Belmar et al. 2010). La incorporación de cultivos debió modificar los modos de vida, por los requerimientos del ciclo de siembra-cosecha y de la preparación y cuidado de los suelos y las plantas durante su desarrollo. No obstante, los huertos de quinoa no presentan mucha demanda durante su crecimiento y pudieron integrarse bastante bien a la movilidad que tradicionalmente tuvieron los cazadoresrecolectores para obtener las fuentes naturales de alimento.

La quinoa puede haber contribuido a una readecuación de los equilibrios nutritivos en una población que está cambiando sus hábitos alimentarios. El valor promedio de $\delta^{15} \mathrm{~N}(4,5 \%)$ obtenido de 7 individuos señala un bajo consumo de carne, importante fuente de proteínas de los cazadores recolectores del período Arcaico. Esta alimenta- 
ción más «vegetariana» de dichas comunidades pudo ser propiciada por el alto aporte proteico y la diversidad de aminoácidos esenciales de alta calidad que aporta la quinoa como alimento. Los valores de isótopos estables de carbono (promedio $\delta^{13} \mathrm{Ccol}$ $-20,1 \%$ y $\delta^{13} \mathrm{Cap}-12,2 \%$ ) son coherentes con una alimentación basada en recursos C3, entre los que se cuenta la quinoa y los frutos silvestres (Falabella et al. 2007). Otro factor relevante en estos procesos de cambio es la fabricación de piezas de alfarería que se inicia en esta época. El uso de ollas de cerámica beneficia la preparación de la quinoa y también otros productos silvestres, facilitando una adecuada cocción y posterior proceso de digestión. En efecto, una de las hipótesis sobre los orígenes de la tecnología alfarera en el centro de Chile, es que fue un fenómeno local fruto de un largo proceso de observación y experimentación asociado a las actividades de preparación de alimentos realizadas en torno a los fogones (Falabella y Planella 1988-89). No obstante, dado que no existen evidencias arqueológicas de las etapas de experimentación alfarera, también se ha planteado que los conocimientos técnicos sobre su manufactura, así como la introducción de los primeros cultivos, derivarían de contactos con vecinos. Sus expresiones particulares son de características netamente locales; ambos aspectos pueden estar más relacionados con la preparación y consumo de recursos durante prácticas ceremoniales y de orden social que con la alimentación cotidiana (Sanhueza y Falabella 1999-2000, Sanhueza et al. 2003). Estos son temas que siguen abiertos en la arqueología de la región.

\section{Los grupos Bato del período Alfarero Temprano}

En Chile central, desde ca 200 d.C. se evidencia una nueva realidad cultural, marcada por la coexistencia de una variedad de contextos reflejo de grupos humanos con identidades sociales diferenciadas. Algunos de ellos, como Bato, Llolleo y los cazadores-recolectores en la cordillera, han sido estudiados y descritos con cierto nivel de resolución y otros, representados a veces por un sitio solamente, aún son parte de una variabilidad que se sigue investigando (Sanhueza et al. 2003, Cornejo y Sanhueza 2011a).

Los grupos Bato tienen las fechas más tempranas y se traslapan con las Comunidades Alfareras Iniciales, con las cuales comparten bastantes similitudes culturales (p.ej. el uso de tembetá, asas mamelonares) y se proyectan temporalmente hasta fines del período Alfarero Temprano (1200 d.C.). Muestran cambios en sus prácticas funerarias y en ciertas características de las vasijas, pero mantienen una «fuerte tradición cazadora recolectora» (Sanhueza et al. 2003:44), con tradiciones líticas del Arcaico y movilidad dentro de sus territorios, tanto a lo largo de la costa como en los valles del interior. En general, los asentamientos son de corta duración, emplazados en torno a quebradas y lagunas o zonas con napas freáticas altas. Se organizan en unidades sociales pequeñas, con escasas evidencias de formas de integración social a nivel regional. Los registros arqueobotánicos de sitios estudiados muestran que ellos también mantuvieron una dieta en gran parte basada en recursos silvestres, siendo los productos cultivados sólo un ingrediente más de los alimentos. Entre éstos sin duda la quinoa es el más ubicuo y aparece por primera vez el maíz (Zea mays), aunque con una representación escasa. 
Cuadro 2: Rango de tamaños de Chenopodium quinoa en distintos sitios analizados

\begin{tabular}{|c|c|c|c|c|}
\hline \multirow[t]{2}{*}{$\begin{array}{l}\text { Adscripción } \\
\text { cultural }\end{array}$} & \multirow[t]{2}{*}{ Sitio } & \multirow[t]{2}{*}{ Descripción } & \multicolumn{2}{|c|}{$\begin{array}{l}\text { Rango de tamaños } \\
\text { (diámetros en } \mathrm{mm} \text { ) }\end{array}$} \\
\hline & & & Mínimo & Máximo \\
\hline \multirow{2}{*}{ Período Arcaico IV } & Las Morrenas 1 & Chenopodium cf. C. quinoa & 1,4 & 1,5 \\
\hline & El Plomo & Chenopodium cf. C. quinoa & 0,8 & 1 \\
\hline \multirow{4}{*}{$\begin{array}{l}\text { Comunidades } \\
\text { Alfareras } \\
\text { Iniciales }\end{array}$} & Lonquén & Sin radícula & 0,8 & 1 \\
\hline & Lonquén & Entero & - & 1 \\
\hline & Estación Quinta Normal & Sin radícula & 0,5 & 1,7 \\
\hline & Estación Quinta Normal & Entero & - & 1,5 \\
\hline \multirow{5}{*}{ Grupos Bato } & Las Brisas 3 & Entero & 1,2 & 1,5 \\
\hline & Las Brisas 3 & Sin radícula & 0,8 & 1 \\
\hline & El Membrillar 2 & Sin radícula & 1 & 1,5 \\
\hline & ENAP 3 & Sin radícula & 0,8 & 1,2 \\
\hline & ENAP 3 & Entero & - & 1,4 \\
\hline \multirow{4}{*}{ Grupos Llolleo } & La Granja 1 & Chenopodium sp. & 1 & 1,3 \\
\hline & La Granja 1 & Entero & 1 & 1,5 \\
\hline & La Granja 3 & Entero & - & 1,8 \\
\hline & Tejas Verdes 4 & Entero & 1,2 & 1,5 \\
\hline \multirow{8}{*}{$\begin{array}{l}\text { Periodo } \\
\text { Intermedio } \\
\text { Tardío }\end{array}$} & Las Brisas 10-14 & Entero & 1,7 & 1,8 \\
\hline & Las Brisas 10-14 & Sin radícula & 1,2 & 1,3 \\
\hline & Tejas Verdes 1 & Entero & 1,5 & 2 \\
\hline & Popeta & Sin radícula & 0.8 & 1,6 \\
\hline & Popeta & Entero & 0,8 & 1,5 \\
\hline & Puangue & Sin radícula & 0,9 & 1,5 \\
\hline & Laguna de Matanzas & Entero & 1,5 & 2 \\
\hline & Puangue & Entero & 0,9 & 1,3 \\
\hline \multirow{4}{*}{ Periodo Tardío } & Cerro Mercachas & Sin radícula & 0,7 & 1,2 \\
\hline & Cerro Mercachas & Entero & 1,1 & 1,5 \\
\hline & Cerro La Cruz & Sin radícula & 0,6 & 1,3 \\
\hline & Cerro La Cruz & Entero & 0,8 & 1,8 \\
\hline Momentos históricos & Las Tejas 3 & Entero & - & 2 \\
\hline
\end{tabular}

La quinoa se registra en sitios costeros desde la ribera sur del río Aconcagua, como El Membrillar 2 y ENAP 3 (140 a 540 d.C.) hasta el sur del río Maipo, como Las Brisas 3. En general los tamaños no van más allá de $1,5 \mathrm{~mm}$ y algunos presentan daños tafonómicos que pueden deberse a actividades de procesamiento o a las condiciones de depósito (Cuadro 2). En Las Brisas 3, además de quinoa se encontró un fragmento de cariopses de 
Zea mays en el estrato fechado ( 38 a.C. a 224 cal d.C.) y un fragmento de coronta o marlo de maíz, en la capa fechada 443 a 989 cal d.C. (Rivas y González 2008).

Si bien restos de maíz están presentes desde fechas tempranas en contextos Bato, no parece haber tenido importancia en la dieta. Los valores isotópicos obtenidos de individuos Bato, tanto de la costa como del interior, sugieren un consumo escaso e irregular de esta planta. En la costa (9 individuos), considerando que parte de la alimentación proviene de recursos del mar, los valores $\delta^{13} \mathrm{Ccol}-18,0 \% \pm 1,0$ y $\delta^{13} \mathrm{Cap}-10,9 \% \pm 1,5$ reflejan un aporte prácticamente nulo de plantas $\mathrm{C} 4$. En el interior (9 individuos) en cambio, donde no hay aporte marino, tienen un promedio de $\delta^{13} \mathrm{Ccol}-16,7 \pm 2,1 \%$ y $\delta^{13} \mathrm{Cap}-9,3 \pm 2,0 \%$. La variabilidad entre individuos es significativa, con máximos y mínimos de $\delta^{13} \mathrm{Ccol}$ entre $-20,6$ y -13,6\%. Esta variabilidad es común en situaciones iniciales de consumo/uso de este recurso. No obstante las fechas directas de los individuos analizados, a excepción de la muestra que presentó el valor más empobrecido $\left(\delta^{13} \mathrm{Ccol}-20,6 \%\right.$ ), son todas posteriores al 500 d.C. Esto deja abierta la posibilidad que no sean los grupos Bato propiamente tales quienes introdujeron el consumo de este cultígeno en la región sino, como se describe más abajo, los grupos Llolleo que a partir de esas fechas muestran formas de vida basadas en la horticultura de maíz.

Es probable que sean algunas comunidades Bato las que experimentan con otras especies, como el madi (Madia sativa Mol.), que es una planta nativa americana sembrada por sus propiedades oleaginosas (Ovalle 1969 [1646], Zardini 1992).Con este antecedente, la presencia de la especie cultivada y la silvestre (Madia chilensis Nutt.) en los sitios arqueológicos evidencia su explotación y cultivo por grupos locales. Además, como parecen señalar algunas de sus vasijas cerámicas, que replican la forma de calabazas Lagenaria sp. que facilitan el transporte de líquidos, semillas u otros productos, podrían estar cultivando productos no alimenticios, ampliando el espectro de usos que aportan a los grupos tempranos las plantas cultivadas.

La presencia de especies cultivadas en los registros arqueobotánicos indica que se adquirió de algún modo esta práctica. Las alternativas son múltiples, desde la obtención por intercambio o el surgimiento de plantaciones domésticas a pequeña escala. Restos de vasijas con golletes cribados, a modo de «regaderas» que pueden haber servido o representado una forma de riego inicial, rasgo que se pierde posteriormente en los contextos Llolleo, puede sugerir que estas poblaciones Bato sustentaban una incipiente y restringida horticultura (Planella y Tagle 2004). Los datos disponibles hacen difícil dilucidarlo por ahora.

\section{Los grupos Llolleo del período Alfarero Temprano y la incorporación de nuevos cultígenos}

Los grupos Llolleo, parcialmente contemporáneos con los grupos Bato (400 d.C. a 1200 d.C.) e interdigitados en los mismos espacios, presentan características culturales diferentes en diversos aspectos: en sus adornos corporales, en las prácticas funerarias, en las estrategias expeditivas del instrumental lítico y en las formas y decoraciones de la alfarería (Falabella y Sanhueza 2005-2006). Los Llolleo son claramente horticultores. Manejaron un complejo que incluye Zea mays, Phaseolus sp., 
Lagenaria sp. y Cucurbita sp., además de Chenopodium quinoa. Los atributos morfológicos de la quinoa son similares a los anteriores pero sí se nota mayor ubicuidad y representatividad en los sitios. Los cambios se advierten en el maíz y en la presencia de nuevas especies. Entre éstas cabe destacar ciertas Poaceae con características morfológicas de sus cariopses que las aproximan a las del género Bromus L. (prof. Luis Faúndez, com. pers.) que los pueblos originarios de Chile cultivaban para su alimentación, entre ellas el Bromus mango o magu y Bromus berteroanus o teca. Lo reflejan la evidencia arqueobotánica, los análisis de isótopos estables y se aprecia indirectamente en la disminución de instrumentos líticos de caza, cambios en la morfología de los instrumentos de molienda y en su patrón de asentamiento (Falabella et al. 2008; Planella y Tagle 2004; Sanhueza et al. 2003; Sanhueza et al. 2007). No se conoce bien si primero los grupos familiares se establecen en forma dispersa en terrenos que reconocen como favorables para este tipo de actividades, o si la incorporación de productos que no tienen ancestros de origen local, como lo es Zea mays o Phaseolus sp., promueven dicha situación. En definitiva, hay nuevas exigencias que hacen necesaria la permanencia en los lugares en que se desarrollan las faenas hortícolas, por la dedicación y cuidado de las siembras para lograr buenas cosechas. Los conjuntos residenciales se encuentran en lugares con suelos fértiles cercanos a cursos de agua, muchos de los cuales se anegan con sus crecidas, aportando humedad para el cultivo y fertilizándolos. Esto ocurre principalmente en terrenos del secano costero y que se conocen como «rebaños». La organización y el manejo del territorio son distintos al de sus contemporáneos de la región, siendo de carácter más permanente en consonancia con un modo de vida de base hortícola y con formas de organización supra comunal. Al parecer se efectuaban rituales, probablemente en relación con las actividades y productividad hortícolas, posiblemente a modo de rogativas y reuniones para consolidar lazos de amistad, parentesco y cooperación. En estos lugares de «juntas» la comida y la bebida, así como prácticas tales como fumar, fueron actores fundamentales (Falabella et al. 2001) y en ellos se incorporaron tanto recursos silvestres como cultivados.

Las características de los maíces, hua o uhua en mapudungun, se han estudiado en el valle central a través de mazorcas y granos carbonizados como en el sitio La Granja en la cuenca de Rancagua (500 d.C. a 1000 d.C.). Las mazorcas o corontas son pequeñas, de entre 3 y $5 \mathrm{~cm}$ de largo y las hileras de cariopses, pequeños y redondeados en el ápice, se ordenan en grupos de a dos conformando en total ocho hileras o «corridas». La carbonización, si bien excluye la posibilidad de conocer el color de los granos de este maíz, permite verificar que el grano más frecuente es de tipo «reventador», como es característico del maíz «curahua», maíz duro o de piedra en mapudungun (Falabella et al. 2008; Planella y Tagle 1998). También se podrían adscribir estos ejemplares al maíz de raza Araucano de la zona sur de Chile que presenta ocho corridas y un tamaño que no alcanza los $10 \mathrm{~cm}$ de longitud (Paratori et al. 1990; Timothy et al. 1961).

En la cordillera, en capas del sitio Las Morrenas1 del período Alfarero Temprano, se recuperaron cariopses carbonizados enteros y fragmentados de tipo «reventador» junto a otros cariopses de maíz que presentan una hojuela fina que los cubre desde su parte basal hasta cerca del ápice, atributo que no se ha visto en otros sitios. Son 
de forma alargada con superficie distal ligeramente redondeada; de costado presenta un perfil plano-convexo pero no tienen elementos diagnósticos para adscribirlos a una variedad específica de maíz (Planella et al. 2005). La localización cercana a pasos cordilleranos hacia la vertiente oriental de la cordillera andina, al igual que en el caso de Chenopodium quinoa del período Arcaico IV, facilita las posibilidades de intercambio de conocimientos y cultígenos con grupos transandinos donde se ha reportado una fecha temprana directa sobre Zea mays de $2065 \pm 40$ a.p. en el sitio Gruta del Indio (Rincón del río Atuel, Centro Oeste de Argentina) (Gil et al. 2006: 205).

En la costa, cercano a la desembocadura del río Maipo, en un enterramiento en urna cerámica y su correspondiente galería de sepultación, en un momento ya tardío del período Alfarero Temprano (890 a 1.020 cal. d.C.) del sitio Tejas Verdes 4, Zea mays tiene una representatividad de $11,22 \%$ y Chenopodium quinoa $4,59 \%$ de un total de 196 macrorrestos carbonizados que incluyen Lagenaria sp. y flora nativa. En estos especímenes de maíz el endosperma es bastante parejo y fino, lo que podría indicar otra variedad que la descrita para el sitio La Granja (Planella y Tagle 1998; Planella 2005).

La incorporación de nuevas variedades de maíz en un momento tardío de los desarrollos Llolleo (1048 a 1266 cal d.C) se constata también en corontas de maíz no carbonizadas en la Cueva Cerrillos de la precordillera de Rancagua, almacenadas junto a variedades de porotos, semilla de Lagenaria sp. y frutos de Retanilla ephedra, en una vasija de gran tamaño decorada con bandas rojas formando una estrella (Falabella et al. 2010). Estas corontas son de forma cilíndrica y apuntada hacia su extremo distal, con 16 hileras de cariopses dispuestas de manera levemente desordenada en relación al eje longitudinal. Las cúpulas presentan forma cuadrangular en la superficie exterior de la coronta, con un buen espacio de inserción, y rectangulares en la cara interior.

La presencia de Zea mays en los contextos Llolleo y su utilización para el consumo con fines de prestigio, rituales y/ o económicos, ha sido también detectada por otras líneas de evidencia. Por una parte, a través del estudio de microfósiles recuperados en los contenidos de los ceramios de ofrenda de los enterramientos de la fase II del sitio El Mercurio, en la cuenca de Santiago (300 \pm 140 d.C. a $1080 \pm 90$ d.C.), tanto en el material raspado de las paredes interiores de las vasijas, como en los sedimentos de color amarillo contenidos en jarros en los que se reportó $83.3 \%$ de silicofitolitos Panicoideae en los primeros y $89 \%$ de silicofitolitos Panicoideae en los segundos. Es posible atribuir el sedimento de color amarillo a un brebaje como «muday» por la presencia de fitolitos de una poácea de la misma familia botánica que el maíz (Planella et al. 2010a). Se han analizado igualmente los residuos adheridos a las piedras tacitas del sector Tiltil-Rungue-Montenegro, al norte de la ciudad de Santiago. Allí se han obtenido algunos almidones que corresponden a Zea mays con señales tafonómicas de procesamiento, los que pese a la dificultad de asignación temporal de estos residuos en los bloques con tacitas, se pueden asociar apropiadamente a la intervención de grupos alfareros y horticultores. En los sitios domésticos aledaños, los análisis de carporrestos y microfósiles permitieron confirmar el uso de maíz y una visibilidad mayor de otros recursos vegetales (Planella et al. 2013). Por otra parte, a través de análisis de isótopos estables, se obtuvo en poblaciones de la costa los valores promedio $\delta^{13} \mathrm{Ccol}-15,0 \% \pm 0,9$ y $\delta^{13} \mathrm{Cap}-9,6 \% \pm 0,9$ para ocho individuos que, 
con alimentación marina parcial, reflejan un aporte reducido de plantas $\mathrm{C} 4$. En el interior, en cambio, 14 individuos de 10 sitios, sin dieta marina tienen valores promedio $\delta^{13} \mathrm{Ccol}-13,7 \%$ o 0,6 y $\delta^{13} \mathrm{Cap}-8,0 \% \pm 0,7$ que señalan un aporte importante de Zea mays. El enriquecimiento del carbono y la regularidad de los valores de los individuos estudiados en esos diez sitios contrasta con otros dos sitios Llolleo, El Mercurio y Mateluna Ruz 1, donde los cuatro individuos analizados muestran una diferencia significativa en sus valores promedio: $\delta^{13} \mathrm{Ccol}-16,8 \%$ o $\pm 0,4$ y $\delta^{13} \mathrm{Cap}-9,6 \%$ o 2,7 . Esta diferencia no se justifica por una incorporación incipiente, ya que tienen fechas posteriores al 900 d.C. ni por diferencias de género. Existen una variedad de factores que pueden incidir además de posibles variaciones en los hábitos alimenticios entre individuos y/o comunidades Llolleo. El mayor enriquecimiento del carbono en la niñez de los mismos individuos, estudiada a través de la apatita del esmalte dental, sugiere que los niños fueron alimentados preferentemente con algún preparado a base de maíz, como el ulpo, tal como se mantiene en la actualidad en la zona rural de la región (Falabella et al. 2008).

En el caso de los Phaseolus, las evidencias en los sitios arqueológicos Llolleo son en general más escasas que Chenopodium quinoa y Zea mays. No obstante en el sitio La Granja, que tiene sectores diferenciados con áreas de actividad doméstica y áreas de connotación ritual, se obtuvieron cantidades muy distintas de granos carbonizados de porotos, aparentemente Phaseolus vulgaris, entre ellos. En la parte doméstica presentan una densidad de 1,73 y en la ritual 0,007 granos por litro (Planella y Tagle 1998).

Los mejores datos sobre los atributos físicos de los porotos provienen de los especímenes almacenados en la vasija Llolleo de la Cueva Cerrillos previamente mencionada, donde hay evidencias de una diversidad de Phaseolus que pudieron resultar de la facilidad para hibridar de esta especie (Singh et al. 1991) o de la introducción de distintas variedades. Se encontraron 16 semillas de porotos junto a maíz y calabaza en estado único de conservación porque los restos no estaban carbonizados, lo que permitió utilizar criterios morfológicos y de color para reconocer sus variedades. Algunos se identificaron como Phaseolus vulgaris que probablemente pertenecen a la raza Chile, una de las tres razas del grupo de germoplasma derivado del acervo genético Andino y que actualmente está adaptado desde el Extremo Norte $\left(18^{\circ} 28^{\prime}\right.$ lat. Sur) hasta Chiloé (42 ${ }^{\circ} 9^{\prime}$ lat. Sur), pero relegado a áreas marginales (Bascur y Tay 2005). Chile es considerado un subcentro de diversidad genética cuyos ecotipos poseen ciertas características que no se encuentran en el germoplasma de otras razas (Singh 1989). Dado que en los reconocimientos realizados en Chile se confirmó la ausencia de poroto silvestre, los especialistas descartan la posibilidad de una domesticación local de la planta. Asignan la diferenciación de la raza Chile a la variación que sufrió el poroto común, después de su introducción desde algún centro de domesticación, como consecuencia de los procesos evolutivos y adaptativos locales (Bascur y Tay 2005). Los porotos de la Cueva Cerrillos presentan granos de tamaño medio, color beige moteado; granos de tamaño pequeño, redondeados color café oscuro; granos de tamaño pequeño, redondeado a ovalado, color negro moteado y granos de tamaño grande, ovalado y aplanado, color negro que podrían pertenecer a un tipo racial diferente (Gabriel Bascur, com. pers. 2005). La fecha AMS 1048 a 1266 cal d.C. 
de uno de estos porotos sitúa el contexto en el momento tardío del período Alfarero Temprano (Falabella et al. 2010).

Creemos que la diferencia en el uso de los recursos silvestres y cultivados, como los señalados más arriba, así como de la caza, formaron parte de la definición de las identidades de los grupos del período Alfarero Temprano. Sugerimos que las preferencias no estaban determinadas tanto por el conocimiento y la disponibilidad de las especies, cuanto por las tradiciones que generación tras generación debieron ir conformando una idea de los productos apropiados para cada cual, en cada lugar y cada ocasión.

\section{Los grupos Aconcagua del período Intermedio Tardío}

A fines del primer milenio, se consolidan profundos cambios en las poblaciones de la región central que configuran un nuevo escenario cultural y social conocido como cultura Aconcagua, entre los ríos Aconcagua y Cachapoal (1000/1200 a 1450 d.C.). Estos afectan prácticamente todas las prácticas sociales y manifestaciones culturales. Los factores que desencadenan los cambios no están claros, pero se piensa que son las mismas poblaciones del período Alfarero Temprano quienes provocan estos cambios y son agentes de los mismos (Cornejo 2010). Cambia la tecnología alfarera, las materias primas utilizadas, formas y decoraciones de las vasijas; las formas y uso de los instrumentos líticos; los ritos mortuorios se desplazan fuera de los lugares de residencia y conforman verdaderos cementerios donde las formas de entierro y la posición en que se disponen los individuos es radicalmente diferente. Se advierte una nueva relación con la fauna, en particular los guanacos, aparentemente «aguachados», es decir, mantenidos intencionalmente cerca de los hogares (Becker 1993). La población Aconcagua mantiene un patrón de asentamiento disperso, con ausencia de jefaturas a un nivel mayor que jefes de linajes, con unidades domésticas localizadas en lugares con buenas fuentes de agua (quebradas, vertientes, ríos, esteros) y de poca pendiente, aptos para los cultivos.

La inmediata sucesión estratigráfica de los contextos Aconcagua sobre las ocupaciones tempranas en diversos sitios del valle del Maipo y la cuenca de Santiago, ha fundamentado la idea de que estas poblaciones usaron los mismos espacios y ambientes, continuando una tradición recolectora de plantas silvestres y productora de recursos cultivados, pero imprimiendo cambios en la escala de la producción, en la selección de los especímenes y en el abanico de las especies consumidas; ello probablemente por razones de diferencias de tamaño de la población y vivienda, así como de las modalidades de residencia. Un mayor énfasis en la presencia de especies consumibles y procesables bajo la forma de chicha es un aspecto del registro arqueobotánico en estos sitios, que sin duda encuentra su correlato con la presencia de vasijas aptas para hervir, macerar, conservar y finalmente para distribuir alimentos en un contexto de comensalidad dentro de las unidades familiares o en agasajos en casos de relaciones sociales (Falabella 2000b; Planella et al. 2010b).

Otras particularidades se advierten en la oposición silvestre/domesticado de los recursos vegetales, los primeros preferentemente recuperados en contextos cordilleranos y de cordones montañosos, como Escobarinos 1 y Huechún 3, donde se 
destacan los taxones silvestres arbóreos y arbustivos, o el Manzano 2 y El Carrizo, caracterizados por la presencia de especies silvestres arbustivas, herbáceas suculentas y por la especie cultivada Madia sativa (madi). En el valle, en cambio, los contextos domésticos de varios sitios (Talagante, Peñaflor, Popeta, Puangue y Las Pataguas) denotan la presencia de una variedad de recursos vegetales, entre los cuales las especies cultivadas adquieren relevancia y son representadas por Zea mays, Chenopodium quinoa y Fabaceae (Quiroz 2000). Algo similar ocurre cerca de la costa al sur del río Maipo en el sitio Laguna de Matanzas. La gama de actividades desempeñadas en estos sitios, concuerda con este registro diverso de taxones, en especial las ollas de cocina que presentan mucho hollín en las superficies exteriores, señal de exposición reiterada al fuego y paredes con altos índices de conductividad, lo que las hace altamente eficientes para cocer (Falabella 2000b). Creemos que estos son indicadores indirectos del incremento o mayor énfasis en las comidas preparadas sobre el fuego y eventualmente en ingredientes con necesidad de tiempos de cocción prolongados para eliminar sustancias tóxicas, como las legumbres.

El estudio de microfósiles complementa la información sobre los cultivos, en particular sobre los contextos de uso. Es el caso del contenido interior de la base de un puco del sitio Fundo Esmeralda, Quillota, al interior de Valparaíso (Venegas et al. 2011), depositado como ofrenda en un entierro, en el que se detectó la presencia de silicofitolitos de Zea mays, Phaseolus sp. y Cucurbita sp. (Planella et al. 2008). Aunque la evidencia etnohistórica señale la existencia de platos indígenas que combinan estos alimentos y que estos taxones aparezcan asociados en la vasija, estos antecedentes no son suficiente aval para proponer que su consumo, en este contexto, fue simultáneo. La evidencia residual rescatada desde las paredes de una vasija corresponde a un promedio de los usos que se le dio durante su vida útil. Una vía para unir estos taxones a modo de ingredientes de una sola preparación culinaria puede lograrse a través del análisis de los daños que presentan los microfósiles, de tal manera que un patrón de daño similar en cada uno de ellos indicaría que fueron procesados según las mismas técnicas de preparación. Aun así, es posible obtener la misma asociación preparando sucesivamente y separadamente cada uno de estos alimentos.

Por otra parte, en asentamientos del valle central, hay una cantidad importante de restos de vasijas para almacenaje, como es el caso del sitio Ruinas de Chada, en Angostura de Paine (Planella y Stehberg 1997) que sugiere la conservación de los productos cultivados y utensilios de molienda de gran capacidad que suponen una intensificación de su procesamiento. En sitios habitacionales como Huechún 3, al norte de la ciudad de Santiago, Puangue en el curso medio del río Maipo, Villa Cardenal Silva Henríquez al este de Catemu, se han reportado grandes cantidades de molinos de canal amplio y manos subrectangulares biconvexas apropiadas para la molienda y la producción a mayor escala de harina de maíz (Stehberg 1981). Los materiales para molienda, en este último, han mostrado microfósiles que avalan la molienda de maíz y quinoa en ellos, además de frutos silvestres como el molle y la palma (Giglio 2012).

En este escenario, se observan mejoras de las semillas de acuerdo con las modificaciones experimentadas en los frutos. Las evidencias, tanto de la quinoa como del maíz, reflejan un aumento de tamaño, mayor variedad inter específica y ubicuidad, lo que supone un uso más constante y generalizado en la población (Cuadro 2). En el 
caso de Zea mays, las mazorcas son de forma alargada con perfil cilíndrico, presentan entre 8 y posiblemente 16 hileras muy regulares y apretadas entre sí. En un fogón del sitio costero Tejas Verdes 1, por ejemplo, los 372 restos entre mazorcas, fragmentos de cúpulas y cariopses carbonizados, representan el $66,7 \%$ del total de macrorrestos analizados, lo que es un porcentaje significativo (Planella 2005).

Los análisis de isótopos estables confirman este aumento en el consumo de plantas C4 (como Zea mays) en las poblaciones del período Intermedio Tardío, en relación a las del período Alfarero Temprano (Falabella et al. 2008). Los valores del carbono aumentan a un promedio $\delta^{13} \mathrm{Ccol}$ de $-11.6 \% \pm 0.8$ y $\delta^{13} \mathrm{Cap}-6.6 \% \pm 0.8$ en los 19 individuos estudiados en valles del interior. En la costa los valores aparecen también enriquecidos, lo que indica que el maíz es parte de la dieta en forma generalizada en todos los ambientes de la región. El mismo estudio muestra valores isotópicos promedio del carbono más positivos en los individuos masculinos que en los femeninos, diferencia que creemos señala un consumo diferencial que se podría atribuir al acceso y consumo preferencial por parte de los hombres, a la chicha o muday de maíz en el marco de las relaciones interpersonales.

Los porotos, al igual que el maíz demuestran cambios en su manejo, aunque éste se registre con menor frecuencia. Los 34 ejemplares en el sitio Tejas Verde 1, poseen rangos de tamaños asimilables a los que se encontraron en La Granja, sugiriendo que el aumento tamaño no es la variable evolutiva relevante de un período a otro y que probablemente lo sea el cambio en las variedades utilizadas. El registro de carporrestos recuperado en el sitio Las Pataguas en la localidad de Valdivia de Paine, al sur de Santiago, a través de un amplio universo de especímenes y especies de la familia Fabaceae, a saber 553 de Fabaceae, dos de Vicia sp., 43 ejemplares de Phaseolus sp. y dos de Phaseolus lunatus (Belmar y Quiroz 2003), dan fe de un proceso de experimentación horticultora que tiende hacia la multiplicación de variedades o por lo menos a la voluntad de hibridar especies, porque las modalidades reproductoras de la familia lo permiten (Ospina et al. 1980). Otro elemento a destacar en el sitio Las Pataguas se relaciona con la magnitud de las dimensiones, el potencial estratigráfico y el carácter ceniciento del rasgo basural desde donde provinieron las muestras. Esas características serían propias de modos de ocupación del espacio doméstico/ habitacional y de los recursos del período siguiente de contacto inca de Chile central y del norte semiárido, de acuerdo con la hipótesis de la intensificación de la producción de recursos y del aumento de la carga de población en los sitios (Belmar y Quiroz 2006a). Asimismo la evidencia disponible de P. lunatus en la región central se circunscribe a los ejemplares de Las Pataguas; en la zona del norte semiárido sus registros tampoco son frecuentes y sólo están asociados a la presencia inca. El contexto Aconcagua del sitio Las Pataguas, al sur de Santiago, fechado en 1440 d.C., se ve entonces permeado por especies distintivas del período Tardío, lo que se vuelve coherente con una interpretación dinámica de los procesos sociales y culturales de la región y del uso y/o préstamos de ciertos hábitos alimenticios por influencia de poblaciones políticamente dominantes. Un caso similar se manifiesta en Casa Blanca 10 , sitio con fechas desde $1045 \pm 90$ d.C. y fragmentería cerámica incaica en las etapas finales de su depósito, que presenta quinoa y maíz en rasgos carbonosos cenicientos, y que a la luz de análisis de residuos en vasijas se complementan con taxones 
tales como el ají de connotación incaica, ausente en los contextos de la región central hasta ese momento (Belmar y Quiroz 2008). Nuevamente se observa, entre la población local Aconcagua tardía, modos locales de producción y de ocupación del espacio pero penetrados diferencialmente, de acuerdo con la importancia estratégica del sitio, por elementos que denotan la presencia inca.

Las evidencias expuestas dejan claro que con las poblaciones Aconcagua se expande y consolida la horticultura (Massone et al. 1998), provocando efectos y modificaciones en las actividades económicas, producción alfarera, costumbres y hábitos sociales relacionados al consumo de alimentos.

\section{Contacto con el Tawantinsuyu durante el período Tardío}

Las instalaciones incas, tanto centros provinciales como secundarios, fueron posibles de administrar eficientemente por el Estado gracias a su conexión a través de un sistema de caminos o red vial que se adaptó a distintas situaciones orográficas, altitudinales y focos de atracción económica y social (Alconini y Malpass 2010). La expansión e incorporación de territorios al Tawantinsuyu, significó el establecimiento de procesos de interdigitación cultural entre grupos locales y el Inca como táctica para la integración de territorios periféricos y como un modo de acceder a la producción local (Sánchez 2004). Hacia ca 1440-1450 d.C. los territorios de Chile central comienzan a ser ocupados en forma discontinua y administrados por contingentes foráneos que traen consigo una serie de innovaciones en lo cultural, social, ritual, organización económica y arquitectura. Por sobre los avances que la arqueología y arqueobotánica han podido reconocer en los grupos Aconcagua, previos a la incursión inca, interesa destacar innovaciones como la ampliación de los terrenos de cultivo y extensión de acequias de regadío, la obtención de tributos a través del trabajo o mita, los trabajos comunitarios o minga y las relaciones sociales con grupos locales, normadas con énfasis en la reciprocidad. Todo ello contribuyó a reorientar y acrecentar los cuidados agrícolas y el almacenaje de productos en respuesta a las nuevas necesidades de administración y alimentación (Rossen et al. 2010), a sustentar los esfuerzos de la población con trabajos organizados bajo otros términos a los acostumbrados y a aceptar los mecanismos de sincretismo en las creencias y rituales, posiblemente en aquellos relacionados con los ciclos anuales de siembra y cosecha. Uno de estos mecanismos, es el uso del estatus cultural del maíz, expresado a través de su capacidad para revivir/recrear el mito de emergencia de la sociedad inca y por extensión, de legitimar el dominio del Tawantinsuyu (Bauer 1996). En la misma línea de interpretación, Harstof y Johannessen (1993) atribuyen al maíz cualidades simbólicas relacionadas con la transformación, relevantes en el entendimiento del proceso de expansión del incanato. Al participar como chicha, la carga simbólica del maíz le otorga un papel fundamental en los ritos y festejos religiosos, ejecutados con los propósitos de trasmitir y legitimar los valores y poder incas.

En este nuevo escenario, también interviene la introducción de términos lingüísticos quechua que se van incorporando a la nomenclatura etno-taxonómica local y que también se refieren a productos vegetales, instrumentos y espacios para la agricultura. 
Ejemplos de ello son chocllo, ch'alla, zara, muti, purutu, kinwa, zapallu, huminta, ch'arki, lampa, chacara (Planella et al. 2010b).

Ciertamente, una estrategia de penetración cultural del imperio, se trasparenta en el riguroso manejo y consumo de recursos vegetales locales versus incas en los sitios ceremoniales y de congregación social, demarcados por la arquitectura y los espacios que ella genera. El Cerro la Cruz, en valle del Aconcagua, ejemplifica emblemáticamente esta disposición distintiva de la evidencia en su plaza intramuro y canchas, estando los espacios de congregación amplia, asociados al consumo de maíz y los más restringidos a las especies silvestres como el quisco y el quilo (Quiroz y Belmar 2013). No ocurre lo mismo en otros sitios rituales, cuando los espacios permanecen indiferenciados, como en Cerro Mercachas (situado en la cima de un cerro con muro perimetral), Villa Cardenal Silva Henríquez y Génesis 1 (sitios con elementos de funebria), donde éstos aparecen asociados. El cementerio Inca-local de Quinta Normal, en la ciudad de Santiago, nos muestra otra arista de estas diferenciaciones, esta vez en relación al tipo de vasija y la combinación de productos revelados por los análisis de microfósiles de los residuos en los enterratorios muestreados (Belmar y Quiroz 2007a). Dos vasijas contienen silicofitolitos de Zea mays (tipo «rondel») y Cucurbitaceae; un puco contiene solo Cucurbitaceae; un aríbalo evidenció Zea mays y Chenopodium quinoa y un cuenco tricromo engobado presentó Zea mays y un tricoma que posiblemente podría corresponder a Phaseolus spp.

El Tambo Ojos de Agua, emplazado en el río Juncal, en la trayectoria hacia el paso cordillerano que comunica con el valle de Uspallata en Argentina, es en cambio un sitio vinculado a la red vial inca. Se trata de una estación de descanso destinada a la dotación de suministros para el tránsito por este camino con una serie de estructuras, entre ellas collcas de almacenaje y acequias (Garceau et al. 2010). En las estructuras se rescató un conjunto abundante de evidencias arqueobotánicas, tanto de plantas cultivadas (quinoa, maíz, ají, poroto, papa y calabaza) así como especies locales silvestres. Los investigadores asocian estos hallazgos con la provisión de alimentos a las caravanas, contribuyendo a descubrir preferencias culturales en la elección de qué plantas serían suministradas y la red de sitios que estarían aportando estos recursos, principalmente cultivados en el valle. No todos los sitios asociados a la red vial presentan estas características. Por ejemplo, en los sitios Pucara del Tártaro y El Tigre, al norte de San Felipe (Pavlovic et al. 2012), no se encontraron plantas cultivadas, lo que puede deberse a la funcionalidad de estos sitios con actividades más efímeras, o a problemas de erosión y conservación (Belmar y Quiroz 2006a, 2007b).

Más al sur, en la cuenca del río Cachapoal el complejo defensivo de Cerro Grande de la Compañía, emplazado en un cerro isla, está compuesto por una plaza en la cima, tres muros perimetrales y numerosas collcas (Planella y Stehberg 1994). El contexto cuenta con análisis arqueobotánicos realizados en recintos y collcas que revelaron la presencia de las especies cultivadas Chenopodium quinoa, Zea mays, Madia chilensis, Helianthus cf. tuberosus y Lagenaria spp. (Rossen et al. 2010), que se relacionaron con almacenaje destinado al intercambio o para el aprovisionamiento ante una situación hostil.

Ha de notarse entonces, que la presencia de macrorrestos de maíz ha sido recurrente en sitios administrativos-económicos, defensivos, como también en sitios habita- 
cionales de la población local, tanto en áreas de fogones dentro de recintos, como en collcas, lo que sugiere su uso como alimento, bebida y también como producto de guarda como excedente de cosechas (Garceau et al. 2010; Planella et al. 1993; Rossen et al. 2010). Ha sido interesante refutar, a través de análisis de isótopos estables, que el consumo de maíz se intensificara entre toda la población, pese a la extensión de las plantaciones (Falabella et al. 2008). Los valores isotópicos de carbono de individuos que con toda probabilidad son indígenas locales, se empobrecen en relación con el período anterior (promedio $\delta^{13} \mathrm{Ccol}-13.1 \% \pm 1.2$ y $\delta^{13} \mathrm{Cap}-7.2 \% \pm 0.9$ ); su uso selectivo puede atribuirse a lo que se ha señalado para otras provincias del Tawantinsuyu (Hastorf y Johannessen 1993). De este modo, el sustento de la población en general habría continuado afianzándose en la caza y los cultivos tradicionales preincaicos, como el madi, la quinoa, porotos, zapallo y flora silvestre de fructificación estacional, junto a productos introducidos como el ají, algunos tubérculos y chuño, además del maíz. Es decir, también en materia de productos de alimentación se aprecia un sincretismo que refleja flexibilidad en los mecanismos de dominio formulados y ejercidos por el Inca en situaciones de frontera (Rossen et al. 2010).

En la mayoría de los sitios estudiados, ciertas similitudes del registro arqueobotánico, como la abundancia, diversidad y aparición de especies o variedades específicas de plantas domesticadas, sugiere un modo de acceder, explotar y procesar los recursos vegetales según patrones definidos por las pautas culturales del Tawantinsuyu, que al parecer implican incremento de la escala y en la intensidad de la explotación, abarcando un amplio espectro de las labores domésticas y de subsistencia e involucrando tanto a las especies de plantas domesticadas como a las especies silvestres locales. En síntesis, estos contextos y la intensidad del depósito ilustran una forma de operar, una organización del trabajo y una presión sobre el ambiente que serían propios de la expansión inca. Sin duda la implantación del sistema económico y social tuvo que causar un cierto impacto en el paisaje vegetal, como resultado de la intensificación de la producción agrícola, lo cual se logra a través de la implementación de nuevas tecnologías, como los sistemas de regadío y la infraestructura de almacenamiento del excedente de producción.

Algo análogo pero más radical ocurrió con la llegada de los españoles, quienes introdujeron nuevas especies y modificaron los hábitos alimenticios locales como parte consustancial de las estrategias para imponer su concepción del mundo y afianzar su dominio. Algunas gramíneas usadas por los indígenas, como el magu, se extinguieron reemplazadas por el trigo, y otras como la quinoa cayeron en desuso por ser consideradas «comidas de indios» y quedaron relegadas a sectores rurales donde se ha mantenido la costumbre de elaborar el pan de quinoa o «covquedahue» y la elaboración de «pihuelo», bebida en base a quinoa y harina tostada (Tagle y Planella 2002).

\section{Conclusiones}

El recorrido de la presencia de recursos domesticados a través de los períodos de la historia prehispánica de Chile central trae a la superficie temáticas de discusión muy distintas según el momento tratado. Estas diferencias descansan principalmente en la distancia temporal que nos separa de cada uno de los períodos y del grado de 
resolución y precisión de la información extraída en cada contexto. Así es que las poblaciones observadas por los conquistadores españoles son retratables con mayor fidelidad, dado que el escenario donde desplegaron sus relaciones socioculturales y sus matices de complejidad son potencialmente perceptibles en los relatos de las crónicas. La posibilidad de centrar la atención en problemáticas de diferente naturaleza de acuerdo con la disponibilidad de información, se considera la fortaleza de nuestra labor, en tanto obliga a profundizar aspectos que pasan desapercibidos en escenarios compuestos o de mayor complejidad.

En el período Arcaico la evidencia dirige la atención hacia los inicios de los procesos de domesticación de la quinoa, dejando al descubierto la aparición de variedades de quinoa entre la zona de Cuyo-Mendoza y la zona central, que se diferencian del fenotipo de los especímenes procedentes de un centro de origen en los Andes Sur-Centrales (Bruno 2006). La presencia temprana de quinoa en estos contextos está ligada con los probables focos de ensayo en esa región del continente y el establecimiento del tipo de «quinoa de nivel de mar», dando a entender que los procesos de domesticación y la manipulación de plantas, a través de probables cruces de especies inter e intra genéricas, están profundamente arraigados en el tiempo y en las poblaciones arcaicas que debieron mantener relaciones más intensas con el entorno vegetal. La permanencia y ubicuidad de la quinoa en los períodos siguientes, se relaciona con el modo de vida móvil, cazador recolector de las Comunidades Alfareras Iniciales y Tempranas, pese a los énfasis diferentes según la tradición de uso de recursos y ocupación del territorio de cada uno. Finalmente en los períodos Intermedio Tardío y Tardío, el cultivo de «quinoa de nivel de mar» perdura junto con la introducción de quinoa altiplánica, notándose incremento en el tamaño de los especímenes, en concordancia con procesos avanzados de manipulación de cultígenos. Culturalmente, su consumo acumula carga simbólica, que ha sido insistentemente capitalizada por el estado inca en sitios de connotaciones rituales y a través de la probable implantación de modos de preparación culinarios.

Otra figura se advierte en la mayor complejidad de la población Llolleo que se consolida de manera reveladora con el afianzamiento del maíz entre los recursos cultivados por estos grupos. Aunque la aparición más antigua de maíz esté consignada en un sitio Bato, los estudios isotópicos entre sus miembros muestran un consumo escaso y variable de este alimento. Es en el seno de los Llolleo donde se manifiesta un consumo regular, que se refrenda a través de la presencia de diferentes variedades/ razas en los sitios de diferente cronología o de su presencia a manera de posible $m u$ day en las vasijas. El maíz curahua «reventador», cuyo ordenamiento de los granos en cuatro dobles hileras es similar a la que se conoce hoy por raza araucana, ostenta la mayor frecuencia en los sitios, sin embargo es posible registrar cambios morfológicos en algunos de ellos, como al comparar los especímenes más antiguos, por ejemplo en el Alero Las Morrenas 1, con los más tardíos, de la cueva Cerrillos. En el período Intermedio Tardío las corontas de maíz experimentan cambios morfológicos y aumento de las hileras de cariopses, con evidencias de un amplio consumo por parte de estas poblaciones. En cambio, en el Período Tardío, en el que tal vez el maíz será objeto de instrumentalización económica/cultural y de producción intensificada, las poblaciones locales propenderán a un consumo menor de este cereal; esta información se de- 
duce de los estudios de isótopos estables, sentando la idea que parte de la producción de Zea mays fue orientada hacia el sostén del sistema de tributación y redistribución de recursos del Tawantinsuyu.

La incorporación del maíz entre los hábitos de consumo de las comunidades Llolleo, dado los cuidados de cultivo que requiere, se ha considerado como el rasgo que les confiere la calidad de horticultores, pero la presencia de Phaseolus en esos contextos le otorga aún más profundidad a esta premisa. La difícilmente explicable escasez de la evidencia del poroto en los sitios arqueológicos, ya sea por razones de conservación o por insuficiente investigación, contrasta con el antecedente de la existencia de una raza Chile, una de las tres reconocidas en el grupo de germoplasma derivado del acervo genético Andino. Cabe aclarar que en ausencia de ancestro silvestre en Chile, el advenimiento de esta raza se debe a la modificación temprana del poroto común, introducido desde algún centro de domesticación, desencadenada a modo de respuesta adaptativa a las condiciones locales. A pesar de disponer de pocos ejemplares, la riqueza contextual de algunos sitios, como La Granja en Rancagua, permitieron apreciar la densidad diferencial de porotos según la funcionalidad; mayor en los espacios domésticos y casi nula en el ritual. En otro registro de información, los excepcionalmente bien conservados porotos de la Cueva Cerrillos han permitido abordar la temática racial o de la variedad de la leguminosa, por cierto emparentada con la raza Chile. Ambos sitios, de fechas tardías dentro del período Alfarero Temprano, entregan las pautas de la discusión sobre la presencia de Phaseolus en el período Intermedio Tardío, durante el cual, los sitios de carácter doméstico como Las Pataguas, que con un amplio y diverso universo de ejemplares carbonizados, remite a un probable manejo de variedades e hibridación inter e intra específica, así como a la incorporación de especies de la Familia Fabaceae, Phaseolus lunatus, por influencia de los Andes Centrales.

La intensidad de la relación con otras especies cultivadas a lo largo de la historia cultural de Chile central puede ser más difícil de definir, dada las reducidas pruebas de su presencia en los contextos. Este es el caso de las Cucurbitaceae, cuyo conocimiento se reafirma con las vasijas cerámicas fitomorfas del período Alfarero Temprano, Lagenaria entre los Bato y Cucurbita entre los Llolleo. La familia Cucurbitaceae se hace notar más durante los períodos Intermedio Tardío y Tardío, en los que se da el consumo variado y enriquecido de recursos, integrando parte de contextos domésticos, rituales funerarios, sitios defensivos o de la red vial incaica.

La escasez de representación no hace concesiones con especies de utilidad muy destacada por los cronistas, como lo es el madi, el magu y la teca. La profundidad temporal de su uso se remonta a los grupos del período Alfarero Temprano. El rastro de estos taxones puede ser seguido en el período Intermedio Tardío y Tardío, en sitios de cordillera y valle indicando que su consumo se acantona en torno a las preferencias de grupos reducidos, pero cuyo cultivo o uso tiende a generalizarse después del período Intermedio Tardío.

Finalmente, la presencia de especies americanas foráneas al contexto local, como el ají (Capsicum spp.), la maravilla (Helianthus spp.) o el poroto pallar (P. lunatus), mantiene estrecha relación con el arribo de especies promovidas por el Tawantinsuyu y participan de toda la gama de sitios funcionales de su esfera de acción. Es intere- 
sante que la presencia de ají, no sólo se ha consignado a partir de semillas dentro de recintos de almacenaje, sino también en residuos adheridos a las paredes de vasijas en el sitio Casablanca 10, lo que sugiere que la vía de incorporación de estos recursos alóctonos podía realizarse mediante la trasmisión y ofrecimiento de saberes culinarios.

En suma, seguir la senda dejada por las plantas cultivadas en la zona central de Chile, es la oportunidad para mirar en perspectiva las formas de apropiación progresiva del ambiente vegetal y territorial y su relación con las disposiciones culturales de los diferentes grupos que habitaron esta región. En el estado de la investigación actual, la información no reúne las condiciones necesarias para dirimir cuestiones atingentes al proceso de domesticación en sí, pero lo cierto es que se aprecia que el proceso suscita acumulación de conocimiento, manejo y una tendencia hacia la inclusión cada vez más amplia de especies domesticadas.

Agradecimientos: Agradecemos los comentarios y sugerencias de dos evaluadores anónimos que han contribuido a mejorar este texto.

\section{Referencias bibliográficas}

Alconini, Sonia y Michael A. Malpass

2010 «Towards a Better Understanding of Inka Provincialism», en Distant Provinces in the Inka Empire, Michael A. Malpass y Sonia Alconini, eds, pp. 279-299. Iowa: University of Iowa Press.

BAscur, Gabriel y Juan TAY

2005 «Colecta, caracterización y utilización de la variabilidad genética en germoplasma chileno de poroto». Agricultura Técnica 65 (2): 135-46.

BAUER, Brian

1996 «Legitimization of the State in Inca Myth and Ritual». American Anthropologist 98 (2): 327-337.

BECKer, Cristian

1993 Algo más que 5.000 fragmentos de huesos. Memoria para optar al título profesional de Arqueólogo. Santiago: Universidad de Chile.

Belmar, Carolina y Luciana Quiroz

2003 Informe análisis carpológico. Sitio Las Pataguas, Valdivia de Paine. Proyecto de rescate arqueológico del sitio Las Pataguas, Investigador responsable Katherine Westfall. Ms.

2006 aLos recursos vegetales de un asentamiento Inka en territorio Diaguita». Anales Museo de Historia Natural de Valparaíso 25: 79-96.

2006 b «Informe Análisis carpológico sitio El Tigre». Informe Fondecyt $N^{\circ} 1040153$, año 2006. Ms

2007a Análisis arqueobotánico: sitio Estación Intermodal Quinta Normal, microfósiles recuperados de los fragmentos cerámicos y ceramios. Informe $2^{\text {da }}$ Etapa Proyecto Extensión Línea 5, Santa Ana-Matucana. Estaciones y Túneles Estaciones. Ms

$2007 \mathrm{~b}$ «Informe Análisis carpológico sitio Pukara El Tártaro». Informe Fondecyt $N^{\circ} 1040153$, año 2007.Ms. 
2008 Informe Análisis de Residuos: Casablanca 10. Informe Fondecyt $N^{\circ} 1040153$, año 2008.Ms

Belmar, Carolina, Luciana, Quiroz y Verónica Reyes

2010 «Las Comunidades Alfareras de la Zona Central son solamente cazadoras-recolectoras: una pregunta enunciada desde el registro carpológico del sitio Estación Quinta Normal, Línea 5 del Metro de Santiago», en Actas del XVII Congreso Nacional de Arqueología Chilena, Tomo II, pp. 1179-1190. Santiago: Sociedad Chilena de Arqueología.

BERTERO, Héctor Daniel

2007 «Quinoas de 'nivel de mar', ¿resultado de una domesticación independiente?», en Libro de Resúmenes, Congreso Internacional de la Quinua, pág. 27. Iquique: CIHDE Universidad Arturo Prat.

Bruno, Maria C.

2006 «A Morphological Approach to Documenting the Domestication of Chenopodium in the Andes», en Documenting Domestication: New Genetic and Archaeological Paradigms, Daniel Bradley, Melinda A. Zeder, Eve Emshwiller y Bruce D. Smith, eds. pp. 32-45. Berkeley: University of California Press.

CORNEJO, Luis

2010 «Hacia una hipótesis sobre el surgimiento de la cultura Aconcagua», en Actas del XVII Congreso Nacional de Arqueología Chilena, Tomo I, pp. 341-50. Santiago: Sociedad Chilena de Arqueología.

Cornejo, Luis, Miguel SAAVedra y Héctor Vera

1998 «Periodificación del Arcaico en Chile central: una propuesta». Boletín de la Sociedad Chilena de Arqueología 25: 36-39.

CORNEJO, Luis y Lorena SANHUEZA

2003 «Coexistencia de cazadores recolectores y horticultores tempranos en la Cordillera Andina de Chile central». Latin American Antiquity 14 (4): 389-407.

2011a «North and South: Hunter-Gatherer Communities in the Andes Mountains in Central Chile». Latin American Antiquity 22 (4): 487-504.

2011b «Caminos que cruzan la Cordillera: el rol del paso del Maipo en la ocupación de la Cordillera en Chile central». Revista Chilena de Antropología 23: 101-22.

Falabella, Fernanda

2000a «El Sitio Arqueológico de El Mercurio en el contexto de la problemática cultural del período Alfarero Temprano en Chile central», en Actas del Segundo Taller de Arqueología de Chile Central. Documento electrónico, http://www.arqueologia. cl/Actas2/Falabella.Pdf, con acceso el 2/7/2015.

2000b «El estudio de la cerámica Aconcagua en Chile central: una evaluación metodológica». Contribución Arqueológica 5: 427-458.

Falabella, Fernanda y M. Teresa Planella

1988-89 «Alfarería temprana en Chile central: Un modelo de interpretación». Paleoetnologica 5: 41-64.

Falabella, Fernanda, y Lorena Sanhueza

2005-06 «Interpretaciones sobre la organización social de los grupos alfareros tempranos de Chile central: Alcances y perspectivas». Revista Chilena de Antropología 18: 105-33. 
Falabella, Fernanda, M.Teresa Planella y Blanca Tagle

2001 «Pipe e tradizione di fumare nelle societa preispaniche del Periodo Agroceramicolo Precoce nella regione centrale del Cile». Eleusis. Nuova Serie 5:137-152.

Falabella, Fernanda, M. Teresa Planella, Eugenio Aspillaga, Lorena Sanhueza y Robert H. TYKOT

2007 «Dieta en sociedades alfareras de Chile central: Aporte de análisis de isótopos estables». Chungara 39 (1): 5-27.

Falabella, Fernanda, M. Teresa Planella y Robert H. Tyкoy

2008 «El maíz (Zea Mays) en el mundo prehispánico de Chile central». Latin American Antiquity 19 (1): 25-46.

Falabella, Fernanda, Luis Cornejo, Itaci Correra, Elvira Latorre, Mario Vásquez y Lorena SANHUENZA

2010 «Los «escondrijos» en reparos rocosos de la zona de El Pangal y sus componentes culturales», en Actas XVII Congreso Nacional de Arqueología Chilena, Tomo II, pp. 719-27. Santiago: Sociedad Chilena de Arqueología.

FuENZALIDA, Humberto

1966 «Climatología», en Geografia Económica de Chile, pp. 31-44. Santiago: CORFO, Editorial Universitaria.

Garceau, Charles, Virginia Mcrostie, Rafael Labarca, Francisco Rivera y Rubén Stehberg 2010 «Investigación arqueológica en el sitio tambo Ojos de Agua, Cordillera del Aconcagua», en Actas XVII Congreso Nacional de Arqueología Chilena, Tomo I, pp. 351-361. Valdivia: Dirección de Museología, Universidad Austral.

GigLio, Antonella

2012 Paleoetnobotánica en un Contexto Ceremonial del Valle del Aconcagua. Caso de Estudio de Villa Cardenal Raúl Silva Henríquez. Tesis inédita. Santiago: Universidad Internacional SEK.

Gil, Adolfo, Robert H. Tyкот, Gustavo Neme y Nicole Shelnut

2006 «Maize on the Frontier; Isotopic and Macrobotanical Data From Central- Western Argentina», en Histories of Maize: Multidisciplinary Approaches to the Prehistory, Linguistics, Biogeography, Domestication and Evolution of Maize, John E. Staller, Robert H. Tykot y Bruce F. Benz, pp. 199-214. Nueva York: Academic Press.

HaRris, David R. y Gordon C. Hillman

1989 «Introduction», en Foraging and Farming. The Evolution of Plant Exploitation, David R. Harris y Gordon C. Hillman, eds, pp.1-7. Londres: Unwin Hyman.

HASTORF, Christine y Sissel JohANNESSEN

1993 «Prehispanic Political Change and the Role of Maize in the Central Andes of Peru». American Anthropologist 95 (1): 115-138.

LAVALlÉE, Danielle

2000 «Les premiers producteurs de l'Amerique du Sud», en Premiers paysans du monde, Jean Guilaine, ed., pp.191-211. París: Édition Errance.

LENZ, Rodolfo

1905-10 Diccionario Etimológico de las voces chilenas derivadas de lenguas indígenas americanas. Santiago: Universidad de Chile. 
López, M. Laura, M. Cristina Bruno y M. Teresa Planella

2015 «El género Chenopodium: metodología aplicada a la identificación taxonómica en ejemplares arqueológicos. Presentación de casos de estudio de la región surandina», en Avances y desafios metodológicos en Arqueobotánica. Miradas consensuadas y diálogos compartidos desde Suramérica, Carolina Belmar y Verónica Lema, eds., pp. 89-121. Santiago: Universidad SEK.

Massone, Mauricio, Eliana Durán, Rodrigo SÁnchez, Fernanda Falabella, Florence Constantinescu, Nuriluz Hermosilla y Rubén Stehberg

1998 «Taller cultura Aconcagua: evaluación y perspectivas». Boletín de la Sociedad Chilena de Arqueología 25: 24-30.

NúÑez, Lautaro, Juan Varela, Rodolfo Casamiquela, Virgilio Schiappacasse, Hans Niemeyer y Carolina Villagrán

1994 «Cuenca de TaguaTagua en Chile: El ambiente del Pleistoceno y ocupaciones humanas». Revista Chilena de Historia Natural 67 (4): 503-519.

Ospina, Héctor Fabio, Rigoberto Hidalgo, Leonard Song y Paul L. Gepts

1980 Diversidad genética de las especies cultivadas del género Phaseolus. Colombia: Editores CIAT (Centro de Agricultura tropical).

Ovalle, Alonso de

1969 Histórica relación del Reino de Chile [1646]. Santiago: Editorial Universitaria.

Paratori, Orlando, Rodrigo Sbártaro y Claudio Villegas

1990 Catálogo de recursos genéticos de maíz de Chile. Boletín Técnico 165. Santiago: INIA.

Pavlovic, Daniel, Andrés Troncoso, Rodrigo Sánchez y Daniel Pascual

2012 «Un tigre en el valle. Vialidad, arquitectura y ritualidad incaica en la cuenca superior del río Aconcagua». Chungara 44 (4): 551-569.

Planella, M. Teresa

2005 «Cultígenos prehispanos en contextos Llolleo y Aconcagua en el área de desembocadura del río Maipo». Boletín Sociedad Chilena de Arqueología 38: 9-23.

Planella, M. Teresa y Ruben Stehberg

1994 «Etnohistoria y arqueología en el estudio de la fortaleza indígena de Cerro Grande de La Compañía». Chungara 26: 65-78.

1997 «Intervención Inka en un territorio de la cultura local Aconcagua de la zona centro-sur de Chile». Tawantinsuyu 3: 58-78.

Planella, M. Teresa y Blanca Tagle

1998 «El sitio agroalfarero temprano de La Granja: Un aporte desde la perspectiva arqueobotánica». Publicación Ocasional del MNHN n52. Santiago: Museo Nacional de Historia Natural.

2004 «Inicios de presencia de cultígenos en la zona central de Chile, períodos Arcaico y Agroalfarero Temprano». Chungara 36 (volumen especial), tomo 1: 387-399.

Planella, M. Teresa, Luis Cornejo y Blanca Tagle

2005 «Alero Las Morrenas 1: Evidencias de cultígenos entre cazadores recolectores de finales del período Arcaico en Chile central». Chungara 37 (1): 59-74.

Planella, M. Teresa, Luciana Quiroz y Carolina Belmar

2008 «Avance de análisis de sedimentos contenidos al interior de un puco del período 
Intermedio Tardío procedente de excavaciones del sitio Fundo Esmeralda, San Pedro, Quillota». Manuscrito.

Planella, M. Teresa, Virginia Mcrostie y Fernanda Falabella

2010a «El aporte arqueobotánico al conocimiento de los recursos vegetales en la población alfarera temprana del sitio El Mercurio», en Actas XVII Congreso Nacional de Arqueología Chilena, Tomo II, pp. 1255-1265. Santiago: Sociedad Chilena de Arqueología.

Planella, M. Teresa, Fernanda Falabella y Blanca Tagle

2010 b «Reconstruyendo cocinas y recuperando sabores de Chile central prehispano», en Historia y cultura de la alimentación en Chile, Carolina Sciolla, comp., pp. 63-85. Santiago: Editorial Catalonia.

Planella, M. Teresa, Gabriela Santander y Virginia Mcrostie

2013 «Estudio morfo-tecnológico y análisis de microfósiles en piedras tacitas de Chile Central», en De las muchas historias entre las plantas y la gente. Alcances y perspectivas de los estudios arqueobotánicos en América Latina, Sneider Rojas-Mora y Carolina Belmar, eds, pp. 113-128. BAR International Series. Oxford: Archaeopress. En prensa.

Planella, M.Teresa, Rosa Scherson y Virginia Mcrostie

2011 «Sitio El Plomo y nuevos registros de cultígenos iniciales en cazadores del Arcaico IV en Alto Maipo, Chile central». Chungara 43 (2): 189-202.

Planella, M. Teresa, Rubén Stehberg, Blanca Tagle, Hans Niemeyer y Carmen del Rio

1993 «La fortaleza indígena del Cerro Grande de La Compañía (Valle del Cachapoal) y su relación con el proceso expansivo meridional incaico», en Actas del XII Congreso Nacional de Arqueología Chilena, Tomo II, pp. 403-421. Santiago: Sociedad Chilena de Arqueología.

Quiroz, Luciana

2000 Hábitos alimenticios en los grupos culturales de la región Central de Chile, durante el contacto cultural con el grupo hispánico: un estudio realizado desde la evidencia vegetal. Trabajo presentado en el Seminario de Etnoarqueología y Etnohistoria, Departamento de Antropología, Facultad de Ciencias Sociales, Universidad de Chile. Ms.

Quiroz, Luciana y Carolina BELMAR

2013 «El rol de las plantas en el entendimiento de la estrategias de dominación Incaica en el sitio Cerro La Cruz (V ${ }^{a}$ Región, Chile)», en De las muchas historias entre las plantas y la gente. Alcances y perspectivas de los estudios arqueobotánicos en América Latina, Sneider Rojas-Mora y Carolina Belmar, eds., pp. 55-73, BAR International Series. Oxford: Archaeopress. En prensa.

Rivas, Pilar y Josefina GonzÁLez

2008 «Las Brisas-3, sitio Agroalfarero Temprano en Santo Domingo. V Región, Chile». Clava 7: 27-49.

Rossen, Jack, M. Teresa Planella y Rubén Stehberg

2010 «Archaeobotany of Cerro del Inga, Chile, at the Southern Inka Frontier», en Distant Provinces in the Inka Empire, Michael A. Malpass y Sonia Alconini, eds., pp. 15-43. Iowa: University of Iowa Press. 
SÁNCHEZ, Rodrigo

2004 «El Tawantinsuyu en Aconcagua (Chile central)». Chungara 36 (2): 325-336.

Sanhueza, Lorena y Fernanda Falabella

1999-2000 «Las Comunidades Alfareras Iniciales en Chile central». Revista Chilena de Antropología 15: 29-47.

SAnhuEZA, Lorena, Mario VÁsquez y Fernanda Falabella

2003 «Las sociedades Alfareras Tempranas de la cuenca de Santiago». Chungara 35 (1): 23-50.

Sanhueza, Lorena, Luis Cornejo y Fernanda Falabella

2007 «Patrones de asentamiento en el período alfarero temprano de Chile central». Chungara 39 (1): 103-115.

SANTANA, Rómulo

1966 «Reseña geográfica de Chile», en Geografía Económica de Chile, pp. 1-17, Santiago: CORFO, Editorial Universitaria.

SingH, Shree P.

1989 «Patterns of Variation in Cultivated Common Bean (Phaseolus vulgaris, Fabaceae)». Economic Botany 43 (1): 39-57.

Singh, Shree P., Paul Gepts, y Daniel G. Debouck

1991 «Races of Common Bean (Phaseolus vulgaris, Fabaceae)». Economic Botany 45 (3): 379-396.

STEHBERG, Rubén

1981 «El complejo prehispánico Aconcagua en la Rinconada de Huechún». Publicación Ocasional MNHN 35. Santiago: Museo Nacional de Historia Natural.

Tagle, Blanca y M. Teresa Planella

2002 La quinoa en la zona central de Chile. Supervivencia de una tradición prehispana. Santiago: Editorial IKU.

TAPIA, Mario

1979 «Historia y Distribución geográfica», en Quinoa y Kañiwa. Cultivos andinos, M. Tapia, H. Gandarillas, S. Alandia, A. Cardozo, A. Mujica, R. Ortiz, V. Otazu, J. Rea, B. Salas y E. Zanabria, eds., pp. 11-19. Bogotá: Instituto Interamericano de Ciencias Agrícolas (IICA) - Centro Internacional de Investigaciones para el Desarrollo (CIID).

Timothy, David H., Bertulfo PEÑa y Ricardo RAmíREZ

1961 Races of Maize in Chile. National Research Council Publication 847. Washington D.C.: National Academy of Sciences.

VAldivia, Pedro de

1960 «Cartas al Emperador Carlos V» [1545], en Crónicas del Reino de Chile, Tomo 131: 1-74. Biblioteca de Autores Españoles. Madrid: Atlas.

Venegas, Fernando, Hernán Avalos y Andrea SAunier

2011 Arqueología e historia del curso medio e inferior del río Aconcagua. Valparaíso: Ediciones Universitarias de Valparaíso.

Villa-Martínez, Rodrigo, Carolina Villagrán y Bettina Jenny

2003 «The Last 7500 cal yr B.P. of Westerly Rainfall in Central Chile Inferred from 
a High-Resolution Pollen Record from Laguna Aculeo $\left(34^{\circ} \mathrm{S}\right) »$. Quaternary Research 60: 284-293.

VIVAR, Gerónimo de

1979 Crónica y relación copiosa y verdadera de los Reinos de Chile [1558]. Berlin: Colloquium Verlag.

WiLsON, Hugh D.

1988 «Quinua biosystematics I: Domesticated populations». Economic Botany 42 (4): 461-77.

ZARDINI, Elsa

1992 «Madia sativa Mol. (Asteraceae-Helianthaceae-Madiinae): An Ethnobotanical and Geographical Disjunct». Economic Botany 46 (1): 34-44. 